\title{
ANALISIS TITIK IMPAS DAN RESIKO PENDAPATAN USAHA TERNAK ITIK PETELUR DI DESA SUGIH WARAS KECAMATAN BELITANG MULYA KABUPATEN OGAN KOMERING ULU TIMUR
}

\author{
ENDANG LASTINAWATI \\ Program Studi Agribisnis Fakultas Pertanian Universitas Baturaja \\ email : endang.lastinawati@gmail.com
}

\begin{abstract}
This study aimed to analyze the break even point and the risk of laying ducks farm income in Sugih Waras Village, Belitang Mulya Subdistrict, Ogan Komering Ulu (OKU) Timur District. The research location is determined on purposive and make all laying duck farmers using cages $15 \times 5 \mathrm{~m}$ and $15 \times 6 \mathrm{~m}$ or raising \pm 150 laying ducks in Sugih Waras Village as the respondents of this study (census methods). The results showed that laying ducks farmers in Sugih Waras Village reach the break even point at the time of production by 740 egg per month with a price is $\mathrm{Rp} 1.111 .675,13$ per egg. Laying ducks farm in Sugih Waras Village likely losses indicated by the variation coefficient of 1,026 and the lower limit revenue of -1.380.102,9.
\end{abstract}

Keywords : break even point, the risk of income, laying ducks

\section{PENDAHULUAN}

Pengembangan komoditas peternakan memiliki potensi yang masih cukup besar, sehingga menjadi alasan utama untuk menjadikan subsektor peternakan sebagai salah satu sumber pertumbuhan ekonomi bagi sektor pertanian saat ini. Pengaruh subsektor peternakan yang besar terhadap kehidupan masyarakat Indonesia tidak terlepas dari fungsi dasar subsektor peternakan sendiri dalam pemenuhan pangan dan gizi masyarakat Indonesia, terutama pemenuhan kebutuhan hewani (Arianti dan Suryani, 2013).

Perkembangan usaha peternakan unggas di Indonesia relatif lebih maju dibandingkan usaha ternak yang lain. Hal ini tercermin dari kontribusinya yang cukup luas dalam memperluas lapangan kerja, peningkatan pendapatan masyarakat, dan terutama sekali dalam pemenuhan kebutuhan makanan bernilai gizi tinggi (Budiraharjo, 2009). Industri perunggasan di Indonesia hingga saat ini berkembang sesuai dengan kemajuan perunggasan global yang mengarah kepada sasaran mencapai tingkat efektifitas (produktivitas) dan efisiensi usaha yang optimal. Namun upaya pembangunan industri perunggasan tersebut masih menghadapi tantangan global yang mencakup kesiapan daya saing produk, terutama bila dikaitkan dengan lemahnya kinerja penyediaan bahan baku pakan yang merupakan $60-70 \%$ dari biaya produksi, karena sebagian besar masih sangat tergantung dari impor (Departemen Pertanian dalam Rohmad, 2013).

Itik merupakan salah satu jenis unggas yang dikenal oleh masyarakat, terutama produksi telurnya. Selain produksi telur, dagingnya juga mudah diperoleh dengan harga yang terjangkau menurut ukuran pendapatan masyarakat pedesaan. Ternak itik merupakan salah satu usaha yang cukup berkembang di Indonesia meskipun tidak sepopuler ternak ayam. Jika dibandingkan dengan ternak unggas yang lain, ternak itik memiliki kelebihan, diantaranya mampu menghasilkan telur dalam 24 bulan masa produktif yang panjang, serta memiliki daya tahan yang cukup baik terhadap penyakit. Oleh karena itu, usaha ternak itik memiliki resiko relatif kecil sehingga sangat potensial untuk dikembangkan (Nugraha et al., 2013).

Itik petelur adalah itik yang diternakkan dengan tujuan utama menghasilkan telur. Indonesia memiliki keragaman jenis itik. Biasanya nama itik diberikan sesuai dengan nama daerah utama pengembangannya, misalnya itik Alabio, Mojosari, Bali, ataupun Tegal (Wicaksono, 2014). 
Di Kabupaten Ogan Komering Ulu (OKU) Timur, pengembangan peternakan baik untuk ternak besar, ternak kecil maupun unggas cukup baik dan potensial. Terdapat 99.990 ekor populasi itik petelur di Kabupaten OKU Timur pada tahun 2014, dan Belitang Mulya merupakan kecamatan yang paling banyak populasi itik petelurnya (BPS OKU Timur, 2014). Salah satu desa di Kecamatan Belitang Mulya yang menjadi sentra itik petelur adalah Sugih Waras. Desa Sugih Waras memiliki populasi itik petelur sekaligus peternak itik terbanyak di antara sebelas desa lainnya. Meskipun sangat potensial untuk dikembangkan, usaha ternak itik di Desa Sugih Waras banyak yang masih dilakukan secara tradisional, dengan penggembalaan berpindah-pindah dari sawah ke sawah. Tetapi karena kian menyempitnya areal penggembalaan itik, banyak pula yang mulai meninggalkan usaha tradisional ini.

Salah satu usaha yang diharapkan mampu mengatasi masalah ini adalah dengan mengalihkan sistem pemeliharaannya dari sistem tradisional ke sistem intensif dengan cara ternak itik di dalam kandang. Pengandangan ini cukup efektif karena itik tidak lagi digembalakan di sawah untuk mencari makan sendiri, tetapi cukup diberikan pakan dan minum yang disediakan dalam kandang. Keuntungan pemeliharaan itik petelur secara intensif adalah produktivitas telur lebih tinggi, keselamatan dan kesehatan pada itik lebih terjamin dan biaya pemeliharaan yang lebih efisien. Berdasarkan data Litbang Kementerian Pertanian RI, Produksi telur itik yang dipelihara dengan cara digembalakan rata-rata dapat menghasilkan 124 butir/ekor/tahun, sedangkan dengan sistem pemeliharaan intensif telurnya dapat mencapai lebih dari 200 butir/ekor/tahun. Dari perbandingan ini, itik yang dikandangkan mampu menghasilkan telur lebih banyak dengan produksi lebih stabil dan lebih baik mutunya daripada yang digembalakan. Sehingga permintaan pasar akan telur itik yang masih tinggi dapat kita manfaatkan dengan memaksimalkan produksi telur dari itik yang kita ternak secara intensif (Wicaksono, 2014).

Break Even Point (BEP) adalah suatu teknik untuk mengetahui pada volume produksi berapa suatu usaha, dalam hal ini usaha ternak itik petelur, tidak mengalami kerugian dan tidak pula memperoleh laba. Hal ini erat kaitannya dengan efisiensi produksi dalam sebuah usaha, agar mampu menghasilkan produk secara optimal dari besaran volume produksi yang paling minimal yang harus diusahakan. Volume produksi dapat berupa minimal jumlah ternak yang harus dipelihara, atau jumlah telur yang harus dihasilkan (BEP unit), dan berupa nilai produk yang minimal ditawarkan pada konsumen (BEP harga, rupiah) (Andanawari, et al., 2013).

Bagaimanapun, setiap usaha diharapkan dapat memberikan keuntungan yang besar dengan tingkat resiko sekecil-kecilnya. Menurut Siregar dalam Soekartawi et al (1993), resiko dalam suatu usaha mencakup kemungkinan kerugian dan keuntungan di mana tingkat resiko tersebut ditentukan sebelum suatu tindakan diambil berdasarkan ekspektasi atau perkiraan seorang pengambil keputusan. Ketidakpastian diartikan sebagai suatu situasi di mana seorang pengambil keputusan tidak mengetahui hasil dari setiap tindakan yang mungkin dapat dilakukan saat mengambil keputusan, karena setiap tindakan memiliki lebih dari satu hasil yang mungkin akan terjadi.

Berdasarkan latar belakang yang telah diuraikan sebelumnya, maka menarik untuk diteliti tentang titik impas dan resiko pendapatan usaha ternak itik petelur di Desa Sugih Waras Kecamatan Belitang Mulya Kabupaten OKU Timur.

\section{METODOLOGI PENELITIAN}

Penelitian dilaksanakan di Desa Sugih Waras Kecamatan Belitang Mulya Kabupaten OKU Timur pada bulan Agustus sampai bulan Desember 2015. Lokasi penelitian dipilih secara sengaja (purposive) dengan pertimbangan bahwa Desa Sugih Waras merupakan sentra itik petelur di Kecamatan Belitang Mulya Kabupaten OKU Timur. 
Terdapat 130 peternak itik petelur di Desa Sugih Waras, tetapi yang menjadi populasi peternak dalam penelitian ini adalah peternak yang memiliki populasi itik petelur rata-rata 150 ekor dengan luas kandang 15 x $5 \mathrm{~m}$ dan $15 \times 6 \mathrm{~m}$. Berdasarkan kriteria tersebut, ada 15 peternak yang memenuhi kriteria, sehingga semua peternak sebanyak 15 orang tersebut diambil secara sensus sebagai sampel penelitian.

Untuk menjawab masalah pertama, digunakan analisis titik impas (BEP). Analisis BEP menurut Prawirosentono (2001), dapat dihitung dengan rumus sebagai berikut :

$$
\begin{aligned}
& \operatorname{BEP}(\text { unit })=\frac{\mathrm{BTp}}{\frac{\mathrm{Py}}{\text { unit }}-\frac{\mathrm{BV}}{\text { unit }}} \\
& \operatorname{BEP}(\mathbf{R p})=\frac{\mathrm{BTp}}{1-\frac{\mathrm{BV}}{\mathrm{Py}}}
\end{aligned}
$$

Di mana :

BTp = biaya tetap $(\mathrm{Rp} / \mathrm{bulan})$

$\mathrm{BV} \quad=$ biaya variabel $(\mathrm{Rp} / \mathrm{butir})$

Py $\quad=$ harga produk $(\mathrm{Rp} / \mathrm{butir})$

Untuk menganalisis resiko pendapatan usaha ternak itik petelur, digunakan metode hasil yang diharapkan (E) dan besarnya resiko (V) yang diadopsi dari Hernanto (1989) dengan rumus sebagai berikut :

$$
\mathrm{E}=\frac{\sum_{\mathrm{i}=1}^{\mathrm{n}} \mathrm{Ej}}{\mathrm{n}}
$$

Di mana :

$\mathrm{E}=$ pendapatan rata-rata yang diharapkan

Ei = pendapatan satu kali periode pengamatan

$\mathrm{n} \quad=$ jumlah periode pengamatan

Selanjutnya, ukuran ragam/varians dan simpangan baku menjelaskan resiko dalam arti kemungkinan menyebarnya hasil pengamatan sebenarnya di sekitar hasil rata-rata yang diharapkan (Nasaruddin, 2000). Di mana ragam/varians $\left(\mathrm{V}^{2}\right)$ dan simpangan baku (V) dihitung dengan menggunakan rumus :

$$
V^{2}=\frac{\sum_{i=1}^{\mathrm{n}}(\mathrm{E} 1-\mathrm{E})^{2}}{(\mathrm{n} 1)}
$$

Sedangkan :

$$
\mathrm{V}=\sqrt{\mathrm{V}^{2}}
$$

Koefisien variasi $(\mathrm{CV})$ digunakan untuk memilih alternatif yang memberikan resiko terendah dari pendapatan dengan rumus sebagai berikut :

$$
\mathrm{CV}=\frac{\mathrm{V}}{\mathrm{E}}
$$


Menurut Pappas dan Hirschey dalam Heriani et al (2013), untuk mengukur batas bawah pendapatan usaha ternak itik petelur digunakan rumus berikut :

$$
\mathrm{L}=\mathrm{E}-2 \mathrm{~V}
$$

Di mana :

L = batas bawah pendapatan

Dari rumus-rumus di atas, diperoleh hubungan antara batas bawah pendapatan dengan nilai koefisien variasi. Apabila nilai $\mathrm{CV}>0,5$ maka nilai $\mathrm{L}<0$ yang berarti bahwa pada setiap proses usaha ternak itik petelur ada peluang usaha tersebut memperoleh kerugian. Sebaliknya, jika nilai $\mathrm{CV} \leq 0,5$ maka nilai $\mathrm{L} \geq 0$ yang berarti usaha ternak itik petelur selalu mendapatkan keuntungan.

\section{HASIL DAN PEMBAHASAN}

\section{Karakteristik Sampel}

Sampel peternak itik petelur di Desa Sugih Waras Kecamatan Belitang Mulya Kabupaten OKU Timur memiliki karakteristik seperti yang dijelaskan pada Tabel 1.

Tabel 1. Karakteristik peternak itik petelur di Desa Sugih Waras Kecamatan Belitang Mulya Kabupaten OKU Timur

\begin{tabular}{lcr}
\hline \multicolumn{1}{c}{ Karakteristik } & Jumlah (orang) & Persentase (\%) \\
\hline Umur (th) & 4 & \\
a. $35-39$ & 6 & 26,67 \\
b. $41-45$ & 4 & 40,00 \\
c. $46-50$ & 1 & 26,67 \\
d. 51-55 & & 6,66 \\
Jumlah tanggungan keluarga (orang) & 8 & \\
a. 3-5 & 7 & 53,33 \\
b. 6-8 & & 46,67 \\
Tingkat pendidikan & 1 & \\
a. Tidak sekolah & 3 & 6,66 \\
b. SD & 4 & 20,00 \\
c. SMP & 6 & 26,67 \\
d. SMU & 1 & 40,00 \\
e. S1 & & 6,66 \\
\hline Sur :
\end{tabular}

Sumber : data primer, 2015 (diolah)

Data pada Tabel 1 menunjukkan bahwa peternak itik petelur di Desa Sugih Waras Kecamatan Belitang Mulya Kabupaten OKU Timur berada pada usia produktif. Usia akan berpengaruh pada produktifitas peternak dalam menjalankan usaha ternak itiknya. Ditambah dengan jumlah tanggungan keluarga yang cukup banyak, dan didorong oleh tingkat pendidikan yang cukup tinggi, maka seharusnya peternak itik petelur di Desa Sugih Waras dapat menjalankan usahanya dengan baik, karena memiliki wawasan yang lebih luas dan lebih mudah menyerap teknologi baru.

\section{Analisis Titik Impas}

Analisis titik impas (Break Even Point/BEP) dapat dilakukan dengan terlebih dahulu menghitung biaya tetap, biaya variabel dari usaha ternak itik petelur, serta harga jual telur itik. Biaya-biaya yang harus dikeluarkan dalam usaha ternak itik di Desa Sugih Waras Kecamatan Belitang Mulya Kabupaten OKU Timur dapat dilihat pada Tabel 2. 
Tabel 2. Komponen biaya tetap dan biaya variabel rata-rata usaha ternak itik petelur di Desa Sugih Waras Kecamatan Belitang Mulya Kabupaten OKU Timur

\begin{tabular}{lr}
\hline \multicolumn{1}{c}{ Uraian } & Jumlah $(\mathrm{Rp} \mathrm{per} \mathrm{bulan)}$ \\
\hline 1. Biaya tetap & \\
- Penyusutan kandang & 66.667 \\
- Pagar keliling & 35.000 \\
- Bibit itik & 300.000 \\
- Penyusutan alat & 36.333 \\
Biaya Tetap Total & $\mathbf{4 3 8 . 0 0 0}$ \\
2. Biaya variabel & \\
- Pakan & 1.950 .000 \\
- Obat-obatan & 20.000 \\
- Listrik & 7.500 \\
- Tali & 10.000 \\
- Karpet telur & 236.000 \\
- Tenaga kerja & 463.500 \\
Biaya variabel total & $\mathbf{2 . 6 8 7 . 0 0 0}$ \\
Biaya total & $\mathbf{3 . 1 2 5 . 0 0 0}$ \\
\hline
\end{tabular}

Sumber : data primer, 2015 (diolah).

Sedangkan jumlah produksi dan harga telur yang dihasilkan dari usaha ternak itik petelur di Desa Sugih Waras Kecamatan Belitang Mulya Kabupaten OKU Timur dapat dilihat pada Tabel 3 .

Tabel 3. Jumlah produksi dan harga jual rata-rata telur di Desa Sugih Waras Kecamatan Belitang Mulya Kabupaten OKU Timur

\begin{tabular}{clc}
\hline No. & \multicolumn{1}{c}{ Uraian } & Jumlah \\
\hline 1 & Produksi telur (butir/bulan) & 2.958 \\
2 & Harga telur (Rp/butir) & 1.500 \\
\hline
\end{tabular}

Sumber : data primer, 2015 (diolah).

Berdasarkan hasil analisis titik impas (BEP), peternak akan mengalami impas (tidak untung dan tidak rugi) jika dapat menjual telur itik hasil ternaknya sebanyak 740 butir per bulan atau dengan harga Rp 1.111.675,13 per butir. Di Desa Sugih Waras Kecamatan Belitang Mulya Kabupaten OKU Timur, peternak sudah dapat menjual telur itik lebih banyak dengan harga yang lebih tinggi dari jumlah dan harga pada titik impasnya. Dengan demikian, usaha ternak itik petelur di Desa Sugih Waras Kecamatan Belitang Mulya Kabupaten OKU Timur memberikan keuntungan bagi peternaknya sehingga layak diusahakan.

\section{Resiko Pendapatan}

Pendapatan merupakan selisih antara penerimaan dengan biaya total. Sedangkan penerimaan merupakan hasil kali antara jumlah produksi dengan harga jual produk (Soekartawi, 1995). Penerimaan dan pendapatan usaha ternak itik petelur di Desa Sugih Waras Kecamatan Belitang Mulya Kabupaten OKU Timur dapat dilihat pada Tabel 4.

Tabel 4. Penerimaan dan pendapatan usaha ternak itik petelur di Desa Sugih Waras Kecamatan Belitang Mulya Kabupaten OKU Timur

\begin{tabular}{clc}
\hline No. & \multicolumn{1}{c}{ Uraian } & Jumlah \\
\hline 1 & Penerimaan (Rp/bulan) & 4.437 .000 \\
2 & Biaya Total (Rp/bulan) & 3.125 .000 \\
3 & Pendapatan (Rp/bulan) & 1.312 .000 \\
4 & R/C & 1,42 \\
\hline
\end{tabular}

Sumber : data primer, 2015 (diolah). 
Setiap bulan, peternak itik petelur di Desa Sugih Waras Kecamatan Belitang Mulya Kabupaten OKU Timur memperoleh pendapatan sebesar Rp 1.312.000,00 dari hasil penjualan telur itiknya. Dengan nilai R/C sebesar 1,42 maka usaha ternak itik petelur layak untuk diusahakan. Tetapi pendapatan peternak dari usaha itik petelur di Desa Sugih Waras Kecamatan Belitang Mulya Kabupaten OKU Timur sebenarnya masih dapat ditingkatkan lagi, karena produktivitas itik petelurnya belum optimal. Hal ini dapat disebabkan karena usaha peternakan yang masih semi tradisional dan belum dilakukan secara intensif. Tabel 5 menunjukkan hasil analisis resiko pendapatan usaha ternak itik petelur di Desa Sugih Waras Kecamatan Belitang Mulya Kabupaten OKU Timur.

Berdasarkan hasil analisis resiko pendapatan, diperoleh nilai koefisien variasi lebih dari 0,5 yang mengakibatkan nilai batas bawah pendapatan kurang dari nol $(\mathrm{L}<0)$. Hal ini berarti bahwa pada setiap proses usaha ternak itik petelur di Desa Sugih Waras Kecamatan Belitang Mulya Kabupaten OKU Timur, ada peluang usaha tersebut memperoleh kerugian. Sehingga agar terhindar dari kerugian, hendaknya peternak itik petelur di Desa Sugih Waras Kecamatan Belitang Mulya Kabupaten OKU Timur dapat mengupayakan usaha ternaknya lebih intensif, memperhatikan pakan dan pemeliharaannya, agar itik petelurnya dapat menghasilkan telur lebih banyak dengan kualitas yang baik, dan menjual harga yang lebih tinggi dari titik impasnya.

Tabel 5. Analisis resiko pendapatan usaha ternak itik petelur di Desa Sugih Waras Kecamatan Belitang Mulya Kabupaten OKU Timur

\begin{tabular}{|c|c|}
\hline Uraian & Nilai \\
\hline Mean $(E)$ & 1.312 .000 \\
\hline Simpangan baku (V) & $1.346 .051,47$ \\
\hline Koefisien variasi $(\mathrm{CV})$ & 1,026 \\
\hline Batas bawah pendapatan (L) & $-1.380 .102,9$ \\
\hline
\end{tabular}

Sumber : data primer, 2015 (diolah)

\section{KESIMPULAN DAN SARAN}

\section{Kesimpulan}

1. Usaha ternak itik petelur di Desa Sugih Waras Kecamatan Belitang Mulya Kabupaten OKU Timur mengalami titik impas pada saat produksi telur sebanyak 740 butir per bulan dengan harga Rp 1.111.675,13 per butir.

2. Usaha ternak itik petelur di Desa Sugih Waras Kecamatan Belitang Mulya Kabupaten OKU Timur berpeluang mengalami kerugian yang ditunjukkan oleh nilai koefisien variasi sebesar 1,026 dan batas bawah pendapatan sebesar -1.380.102,9

\section{Saran}

Usaha ternak itik petelur di Desa Sugih Waras Kecamatan Belitang Mulya Kabupaten OKU Timur sebenarnya layak diusahakan meskipun ada peluang mengalami kerugian.

1. Untuk menghindari resiko kerugian, peternak disarankan untuk lebih intensif dalam melakukan usaha ternak itik petelurnya, melalui pemberian pakan dan pemeliharaan yang baik, agar itik dapat menghasilkan telur dengan jumlah yang optimal dan berkualitas.

\section{DAFTAR PUSTAKA}

Andanawari, S., A. Setiadi, dan L.D. Mahfuds. 2013. Analisis Break Even Point (BEP) Usaha Peterrnakan Itik di Kota Tegal dan Kabupaten Brebes. http://jurnalkampus.stipfarming.ac.id/index.php/am/article/view/59/61 Diakses 12 September 2015.

Heriani, N., W.A. Zakaria dan A. Soelaiman. 2013. Analisis Keuntungan dan Risiko Usahatani Tomat di Kecamatan Sumberejo Kabupaten Tanggamus. JIIA. Vol. 1(2) bulan April 2013. Hal. 169-173. Fakultas Pertanian Universitas Lampung. 
Arianti, R. dan S. Suryani. 2013. Studi Kelayakan Pengembangan Peternakan Puyuh di Kecamatan Tenayan Raya Pekanbaru Riau. Jurnal Ekonomi, Manajemen dan Akuntansi Volume 20(1) Bulan Desember 2013. Hal. 73-92. Fakultas Ekonomi Universitas Islam Riau Pekanbaru. http://www.jurnalkiatuir.com/vol-20-no-1-juni2013/ Diakses 12 September 2015.

BPS OKU Timur. 2014. Data Populasi Hewan Ternak Itik Petelur. Badan Pusat Statistik OKU Timur. Martapura.

Budiraharjo, K. 2009. Analisis Profitabilitas Pengembangan Usaha Ternak Itik di Kecamatan Pagerbarang Kabupaten Tegal. Jurnal MEDIAGRO Volume 5(2) bulan April 2009. Hal. 12-19. Fakultas Pertanian Universitas Wahid Hasyim Semarang

http://id.portalgaruda.org/?ref=browse \&mod=viewarticle\&article=134431 Diakses 12 September 2015.

Hernanto, F. 1989. Ilmu Usahatani. Penebar Swadaya. Jakarta.

Nasarudin. 2000. Ekonomi Produksi. Universitas terbuka. Jakarta.

Nugraha, F.S., M. Mufti dan I.H. Sulistiawan. 2013. Kualitas Telur Itik yang Dipelihara secara Terkurung Basah dan Kering di Kabupaten Cirebon. Jurnal Ilmiah Peternakan. Volume 1(2) bulan Juli 2013. Hal 726-734. Fakultas Peternakan Universitas Jenderal Sudirman. http://jos.unsoed.ac.id/index.php/jip/article/view/643/315 Diakses 12 September 2015.

Prawirosentono, S. 2001. Manajemen Operasi: Analisis dan Studi Kasus. Bumi Aksara. Jakarta.

Rohmad. 2013. Analisis Produktivitas Usaha Peternakan Ayam Pedaging Pola Kemitraan Perusahaan Pengelola di Kecamatan Kandat Kabupaten Kediri. Jurnal Manajemen Agribisnis. Volume 13(1) bulan Januari 2013. Hal. 71-82. http://publikasi.uniskakediri.ac.id/data/uniska/agribisnis/agribisnisvol13no1jan2013/agribisnisvol13no1jan2013-08.\%20Rohmad.pdf Diakses 12 September 2015.

Soekartawi, Rusmadi dan E. Damaijati. 1993. Resiko dan Ketidakpastian dalam Agribisnis, Teori dan Aplikasi. Raja Grafindo Persada. Jakarta.

Soekartawi. 1995. Prinsip Dasar Ekonomi Pertanian : Teori dan Aplikasi. Rajawali Press. Jakarta.

Wicaksono, R.S. 2014. Budidaya Itik Petelur di Indonesia Prospektif. http://ekonomi.inilah.com/read/detail/2100011/budidaya-itik-petelur-di-indonesiaprospektif Diakses 12 September 2015. 